also assists subsequent breakdown so that a following crop may be sown with increased safety. Persistence may be varied according to the formulation of the chemical used. Dr. van der Zweep brought his contribution to an end by appealing for information on the half-life of herbicides, a half-life determined in the first instance in standardized laboratory tests.
Such a system could be extended to field studies where tho variation would be apparent and could bo measured.

The full proceedings of the meeting together with reports of the discussion which followed each paper will be published by Blackwell Scientific Publications, Ltd., later this year.

\title{
COLLOID AND POLYMER SCIENCE
}

C ONTINUING earlier seminars ${ }^{1}$ in the Dopart1 ment of Chemistry of University College, London, nine lectures were given during February 25-March 18. Drs. C. H. Bamford and J. A. Kitchener summarized work (some of which has been published ${ }^{2.3}$ ) on calculation of free-radical reactivity and stability of colloidal model suspensions. Prof. J. A. V. Butler discussed some flow propertics of dilute solutions of deoxyribonueleic acid in $0.2 \mathrm{~N}$ sodium chloride, the rate of shear being varied in the range $0 \cdot 5-30,000 \mathrm{sec}^{-1}$. At the high rate of shear no permanent change of the soluto occurred, but some disentangling of networks. Using the theories of Kuhn and Kuhn ${ }^{4}$ and $\mathrm{Cerf}^{5}$, for the results obtained at low rate of shear, it appears that the deoxyribonucleic acid molocule is somewhat flexible. Dr. P. W. Allen described the grafting of mothylmethacrylate polymers on natural rubber latex using hydrogen poroxide, together with a poly. ethylene amine, as initiators. Under these conditions the graft co-polymer is mainly formed on tho surface of the latex. If oil-soluble initiators are used, polymerization of methylmethacrylate occurs inside the latex. Dr. C. Robinson reviewed recent work ${ }^{6}$ on liquid erystals of synthetic polypeptide and described a now effect : if a concentrated solution of poly- $\gamma$ ethyl-L-glutamate is illuminated with white light, brilliant iridescent colours are reflected. This is explained as an optical analogue of an X-ray powder diagram. There aro indications that deoxyribonucleic acid solutions can also form liquid-crystals.

Prof. A. Katchalsky discussed the application of the thermodynamics of irreversible processes? to the study of colloid-chemical phenomena. The treatment of entropy production as the sum of the products of generalized forces and conjugated flows was outlinod. Sufficiently slow flows are linearly dependent on all the forees operative in the system, through a set of phenomenological equations, the coefficients of which obey (Onsager's law ${ }^{8}$ and constitute a symmetrical matrix. The phenomenological equations provide a convenient formal framework for the description of electrokinetic phenomena ${ }^{9}$, and permit the establishment of the classical saxen rolations on a thermodynamic basis. A similar treatment ${ }^{10}$ of polyelectrolyte solutions leads to new correlations between transport phenomena, such as diffusion, sedimentation and conductance. The thermodynamic approach is useful in tho analysis of membrane permeability ${ }^{11-13}$ : contradictions inherent in the conventional equations do not occur and a consistent set of equations is obtained, suitable for the description of the transport of electrolytes and non-olectrolytes through membranes ${ }^{14}$. The coefficients of these equations were transcribed in torms of frictional forces and distribution coefficients, which eharacterize the interaction of the permeant solutes with the membrane. In the last lecture, Prof, Katchalsky discussed some fundamentals of mechanochemistry ${ }^{15}$

${ }^{1}$ Nature, 182, 762 (1958).

${ }^{2}$ Bamford, C. II., Jenkins, A. D., and Johnston, R., Trans. Faraday Soc., 55, $418(1959)$.

3 Schenkel, J. H., and Kitchener, J. A., Trans. Faraday Soc., 56, 161 $(1960)$.

4 Kuhn, W., Kuhn, H., and Buchner, P., Ergeb. exakt. Naturu., 25, 1 (19351).

${ }^{5}$ C.R. Acad. Sci. Paris, 243, 1875 (1956); 244, 456 (1957).

${ }^{8}$ Robinson, C., Trans. Faraday Soc., 52, 571 (1956). Robinson, C., and Ward, J. C., Nature, 180, 1183 (1957). Robinson, C. F'araday Soc, Discussions, 25, 19 (1958).

${ }^{7}$ Sec Prigogine, I., "Etude thermodynamique des phénomènes irreversibles" (Desoer, Liège, 1947)., de Groot, S. R. "Thermodynamics of Irreversible Processes" (North Holland Pub. Co. Amsterdam, 1951)

${ }^{8}$ Onsager, L., Phys. Rev., a'y, 405 (1930); 38, 2265 (1931).

Mazur, $\mathrm{P}_{\text {, }}$ and Overbeek, I. F., Rec. Trav. Chim. Pays-Bas, 70, 83 (1951).

${ }^{10}$ Katchalsky, A., Alexandrovith, Z., and Kedem, O., "Adv. Chem. Phys." (in the press).

${ }^{11}$ Staverman, A. J., Trans. Faraday Soc., 48, 176 (1952).

${ }_{12}$ Kirkwood, W.. in "Ion Transport across Membranes", 119 (Acad. Press, New York, 1954).

${ }^{13}$ Spiegler, K. S., Trans. Faraday Soc., 54, 1409 (1958).

${ }^{11}$ Kedem, O., and Katchalsky, A., Biochim. Biophys. Acta, 27, 229 (1958).

${ }^{16}$ Katchalsky, A., Tifson, S., Michaeli, T., and Zwick, M., "Size and Shape changes in contractile Polymers" (Pergamon Press, London: New York) (in the press).

\section{EFFECTIVENESS IN INDUSTRY}

$\mathrm{T}$ HE presidential addross of Mr. W. E. Bargett to the Institution of Metallurgists, though specifically directed to that profession, had much of direct interest for other technologies. In discussing the training of both graduates and juniors he pointed out the necessity of realizing that the former, though 'oducated', have still to receive a 'training' oven if during this period they can give little immediate return for their salaries. Equally, "the inefficient utilization of junior people's time is out of keoping with the demands of industry for greater numbers of well-qualified technologists and must be eliminated through sheer economic necessity". It is a general experience that a bright junior is quickly frustrated when called upon to do repetitive work which provides littlo experionce and makes no particular intellectual demand. The interesting suggestion was made that a solution of this problem might be found by employing older people who may have had no special training, but who have sufficient intelligence to learn all that is required to carry out specific operations, appreciating not only what to do but also why it is done in a certain way. Experience has shown that there is no difficulty in filling 
posts of this kind very successfully. They have, indeed, a certain attraction for a particular type of man who is satisfied to continue doing a routine job.

Mr. Bargett, though appreciating the temptation to look for rapid solutions of industrial problems, expressed his strong belief that the effort expended would be more efficiently used in gaining a fuller understanding of the problem itself, that is to say, in finding the best, rather than the quickest, solution. Concluding with a few examples drawn from his own work to illustrate the points made, he mentioned the search for an answer to the urgent problem of overcoming the service-cracking at elevated temperatures of a low carbon steel containing $\frac{1}{2}$ per cent molybdenum. The suggestion that the trouble was due to grain-boundary effects which might be eliminated by the addition of 0.002 per cent of boron proved successful, but also, as a most unexpected by-product, led to the yield-point of the steel being doubled and the tensile strength being raised by 50 per cent. Further work led to the production of a weldable steel with a tensile strength of 70 tons per sq. in. in the air-cooled condition.

\section{HEALTH SERVICES IN THE U.S.S.R.}

$\mathrm{I}_{\mathrm{t}}^{\mathrm{N}}$ October 1958, twenty-three individuals from twenty-one countries and territories were invited by the World Health Organization to visit the U.S.S.R. to study its health services. Some of the members of the group were public health administrators, others were medical specialists, and all were engaged in medical or health work in their own countries. An extensive itinerary was planned by the Government of the U.S.S.R. in order to allow the group to see as much as possible of the country's health services during their stay of a little over five weeks. On their return, the members of the group prepared a report which has recently been published*.

The health services in the U.S.S.R. are organized to meet the requirements of a specific social system and philosophy, and are designed to provide comprehensive medical care for the whole population through the integration of curative and preventive services at all levels of administration. The basic health philosophy in the U.S.S.R. is one of "prophylaxis' by health protection, and it places the responsibility for the health of the people on the State. The Soviet Government has recognized the part played by health in the economy and development of the country, and the fact that certain population groups (children, workers, etc.) require specialized medical attention.

The existing health services of the U.S.S.R. are the result of development during a period of fortyyears research. The complicated structure evolved in this way consists of a number of institutions and functional units so interlocked that the result is a unified system embracing all health disciplines and reaching into every locality in the fifteen constituent republies, to the smallest and most remote villages and farming areas. The basic principle of this structure is highly centralized planning and supervision, coupled with almost complete executive and operational decentralization, permitting about 90 per cent of problems to be dealt with at local levels, without disturbing the general and basic pattern in any way.

The various units constituting the organizational structure of the health services of the U.S.S.R. may be classified into six groups, each group representing a defined function. The six functional groups are: (1) the directing, planning and supervising group ; (2) the academic and scientific group; (3) the

* World Health Organization. Public Health Papers, No. 3 : Health Services in the U.S.S.R. : Report prepared by the Participants in a Study Tour organized by the World Health Organization. Pp. 58 . (Geneva: World Health Organization; London: H.M. Stationery Office, 1960.) 2 Swiss francs; $3 s, 6 d . ; 0.60$ dollar. advisory group ; (4) the educational group; (5) the executive group; (6) the operational group.

The health services of the U.S.S.R., both preventive and curative, are available to the whole population free of charge, regardless of social and economic status. The services of health workers, whether highly trained medical specialists or trained feldschers, reach every home even in the most remote and isolated localities. This is possible because of the 'State' character of Soviet medicine, and although private practice is not forbidden, it is so restricted that it exercises no influence whatever on the general set-up of health services in the country. The State character of Soviet medicine is further illustrated by the structure of the health budget for the Union. The health budget for 1958 makes provision for an expenditure of more than 40 billion roubles. This means that approximately 200 roubles will be spent for every member of the population in one year. But this does not represent the total expenditure for health in the Union, for apart from the official budgets, other bodies and institutions are also required to budget for additional expenditure on health.

The collective farms provide the buildings and equipment, and bear most of the cost of maintenance of their own health units and maternity homes; the health authorities are only responsible for the salaries of medical and para-medical staff. The same applies to industrial concerns. Furthermore, only part of the capital cost of buildings comes from the official health budget. Finally, certain medicines prescribed for ambulatory patients have to be paid for by the patients themselves.

The Soviet concept of health has resulted in a realignment of services which appears to be unique. There are three main medical fields in the U.S.S.R. $(a)$ adult medicine, $(b)$ child medicine, $(c)$ hygiene and sanitation.

Soviet scientists feel quite strongly that a child is not just a miniature adult : it is a different being with its own specific physical and physiological functions, and therefore requires a specific medical approach. Pædiatrics is therefore not a postgraduate speciality of general medicine, but rather a separate study which begins during the undergraduate period. A medical student must choose at the beginning of the third year of his course whether he wants to become a doctor for adults, or a doctor for children, and, depending on the choice, will follow a different line of study.

The third medical field is that of hygiene, which produces graduates known as 'hygienists'. Preventive medicine is divided into $(a)$ personal preventive 